\title{
Therapeutic bronchoscopy with immediate effect: laser, electrocautery, argon plasma coagulation and stents
}

\author{
C.T. Bolliger*, T.G. Sutedja\#, J. Strausz ${ }^{*}$ and L. Freitag
}

ABSTRACT: Minimally invasive diagnostic and therapeutic approaches in medicine have been applied for a more selective and tailored approach to reduce patients' morbidity and mortality. The efficacy of interventional pulmonology for palliation of patients with central airways obstruction has been established and its curative potential for intralesional treatment of early cancer has raised great interest in current screening programmes.

This is due to the fact that surgical resection and systemic nodal dissection as the gold standard is relatively morbid and risky, especially when dealing with individuals with limited functional reserves due to smoking-related comorbidities, such as chronic obstructive pulmonary disease. Furthermore, such comorbidities have been proven to harbour early stage lesions of several millimetres in size without involvement of nodal disease that may be amenable to local bronchoscopic treatment.

Therefore, the success of minimally invasive strategies for palliation and treatment with curative intent strongly depends on the diligent identification of the various factors in lung cancer management, including full comprehension of the limits and potential of each particular technique. Maximal preservation of quality of life is a prerequisite in successfully dealing with individuals at risk of harbouring asymptomatic early lung cancer, to prevent aggressive surgical diagnostic and therapeutic strategies since overdiagnosis remains an issue that is heavily debated.

In the palliative setting of alleviating central airway obstruction, laser resection, electrocautery, argon plasma coagulation and stenting are techniques that can provide immediate relief, in contrast to cryotherapy, brachytherapy and photodynamic therapy with delayed effects. With curative intent, intraluminal techniques that easily coagulate early stage cancer lesions will increase the implementation of interventional pulmonology for benign and relatively benign diseases, as well as early cancer lesions and its precursors at their earliest stage of disease.

KEYWORDS: Argon plasma coagulation, electrocautery, interventional pulmonology, laser resection, stent

\section{CLINICAL BACKGROUND}

Advanced stage lung cancer poses a serious threat to quality of life (QoL) due to local tumour growth and distant metastases [1]. Significant airway obstruction with imminent suffocation requires immediate action to promptly regain the airway passage $[2,3]$. Obstruction is caused by intraluminal tumour growth, extraluminal tumour compression or its combination (fig. 1). The majority of patients referred to interventional

For editorial comments see page 1084 . pulmonologists suffer from end-stage tumour recurrences, failing previous chemoradiotherapy regimens. In addition, imminent suffocation and poor physical condition may provide little room for timely and safe intervention, so immediate action is warranted. Therefore, treatment plans must be diligently considered and executed to obtain an optimal benefit. Tumour coagulation to reduce profuse bleeding, followed by debulking, with additional stenting in case of significant residual extraluminal stenosis, is currently the accepted strategy [2].
AFFILIATIONS

*Lung Unit, Tygerberg Academic Hospital and Faculty of Health Sciences, University of Stellenbosch, Cape Town, South Africa. \#Dept of Pulmonology, Vrije Universteit Academic Hospital, Amsterdam, The Netherlands. "Lungenklinik Hemer, Hemer, Germany.

CORRESPONDENCE

C.T. Bolliger

Lung Unit

Tygerberg Academic Hospital and Faculty of Health Sciences University of Stellenbosch Cape Town South Africa Fax: 27219323105 E-mail: ctb@sun.ac.za

Received:

January 302006

Accepted:

February 242006 


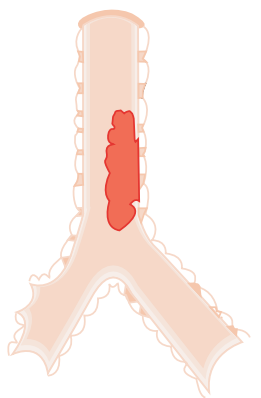

Endoluminal

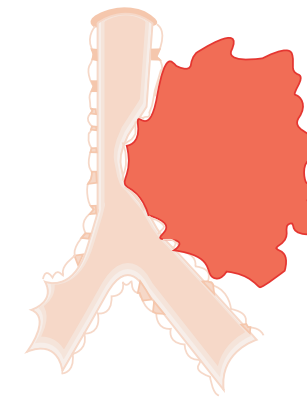

Extraluminal

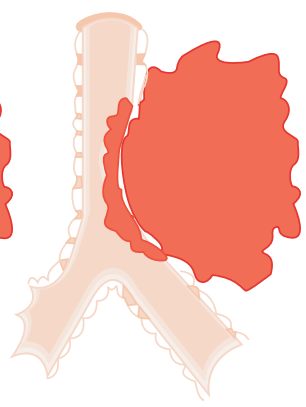

Mixed
FIGURE 1. Schematic illustration of the three basic types of central airway stenosis; a 50\% obstruction at the level of the distal trachea is chosen for each type.

For patients with resectable cancers, radical surgical resection with systemic nodal dissection is the standard approach [4], while lesser resection in the absence of nodal disease is now being explored in many screening strategies $[5,6]$. The persisting chance of developing subsequent cancer primaries in the event of field cancerisation and the fact that many individuals already suffer from smoking-related comorbidities justifies the consideration of using minimally invasive approaches that better preserve QoL [7, 8]. Accurate staging and the definition of early stage lung cancer remain problematic [9]. However, new imaging and staging procedures hold great promise for better tumour assessment [10-12]. Advancements of bronchoscopic techniques allow diligent observation of the target tissues, i.e. in the pre-neoplastic and carcinoma in situ stage. Certain individuals with favourable early lesions can be properly identified and a less invasive approach is appropriate in these subjects [13-20]. The time window before microinvasive cancer develops nodal involvement can be exploited by choosing a tailored approach for each particular lesion in the person at risk that better preserves QoL and has superior cost-effectiveness [21, 22].

Medically unfit patients with early stage cancer have been treated successfully with intraluminal bronchoscopic treatment (IBT) [16-18]. The future of accurate navigational technique, in combination with in vivo microdynamic imaging, can help to extend the reach towards early lesions in the lung parenchyma $[23,24]$, as the majority of them are nonmalignant and tissue biopsy is still required prior to any treatment commencement [25]. A comprehensive strategy, including non- and minimally invasive approaches helps to reduce downstream-related morbidities, mortalities and costs [26-28], as current imaging techniques used in the primary screening have a low positive predictive value fuelling the controversy about overdiagnosis $[29,30]$.

It must not be forgotten that stage shift increases the chance that the individuals at risk may die from nonlung cancerrelated causes [31]. The superior cost-effectiveness of minimally invasive interventions is obvious and already provides a solution for those patients with early stage lung cancer who are considered medically inoperable due to insufficient cardiopulmonary reserves [32]. The role and limitations of various techniques for treating malignant, relatively benign and benign conditions will be discussed.

Previous reviews of endobronchial treatment modalities have usually focused on purely technical aspects of individual techniques used for the treatment of central airway lesions, either with palliative or curative intent. In the current review, it was the intention of the authors to embed these endoscopic modalities in the multimodality approach to central airway lesions, with emphasis on the emerging importance of management of early stage lung cancer.

\section{INDICATIONS}

\section{Palliative care}

Imminent respiratory failure accompanied by symptoms such as stridor and severe dyspnoea requires immediate action [2]. Extensive investigations, e.g. computed tomography (CT) scan, lung function measurements and blood gas analysis, prior to intervention may not be feasible. The immediate action taken is similar to tracheal intubation for life-saving resuscitation. There has been a consensus that individuals presenting with imminent suffocation present with $\geqslant 50 \%$, often with subtotal obstruction of their central airways [3]. With such a clinical presentation, the interventional pulmonologist has to anticipate intra- and extraluminal airways' stenoses (fig. 1). For extraluminal airway stenosis $\geqslant 50 \%$ of the normal lumen, stent implantation is the only choice (see Stents section). In case expertise is lacking, immediate intubation using the fibreoptic bronchoscope, passing distal of the stenosis and cleaning the distal airways of pus and mucus prior to referral, can be lifesaving. Inflation of the tracheal cuff helps compress the tumourous section. Thereafter, the patient can be transported safely to a referral centre for further treatment.

Either by using the rigid scope or working through the endotracheal (ET) tube, the interventional pulmonologist can perform tumour coagulation and debulking in the same session. The rigid scope with its larger working channel provides better access, allowing safer manipulation as ventilation is better preserved [2]. Despite increasing availability of devices suited for the fibreoptic bronchoscope, its blocking effect within the ET tube may limit adequate ventilation, and the smaller working channel may jeopardise safety, especially when dealing with emergency situations.

The ultimate execution of any technique also depends on its cost-effectiveness, the available facility and, more importantly, the expertise of the team. Emergency palliation holds certain risks for procedure-related morbidity and mortality that cannot always be prevented. As personal skills are equally important, there is no ideal interventional strategy that can guarantee a safe outcome based on the negative selection of the individuals treated. Therefore, it should always be understood that technique per se is not the absolute requirement for success.

\section{Treatment with curative intent}

\section{Benign conditions}

Interventional pulmonologists can provide better treatment alternatives than surgery, especially for benign and relatively benign conditions affecting the central airways. For benign tumours (such as hamartoma, chondroma, papillomatosis) and for foreign body removal, surgical interventions should remain the last resort. Any minimally invasive technique that can be initiated to solve the problem before performing major surgery is preferable to an immediate surgical approach [33]. 


\section{Relatively benign conditions}

Significant intraluminal tumour growth that blocks the larger airways may affect the patient's condition due to postobstructive pneumonia. This may justify an initial step of tumour debulking, to improve the patient's condition and better assess tumour status, i.e. tumour node-metastasis (TNM) staging prior to definitive disease management. The patient's general condition, tumour histology, TNM classification and choosing the appropriate strategy should be discussed within a multidisciplinary team in a timely manner. Currently, immediate implementation of a radical invasive approach based on tumour histology alone cannot be justified. Technical refinements allow a balanced, tailored approach for each particular patient based on input from the multidisciplinary team, even in emergency cases. Histology per se is not the absolute factor for great haste, be it surgical exploration or otherwise.

Recent data should lead to more awareness in exploiting interventional pulmonology within the window of opportunity, before a definitive treatment strategy is undertaken. Examples are surgical specimens free of residual tumour (e.g. typical carcinoid), after an initial laser treatment, which resolve post-obstructive pneumonia [34]. Several reports showed the success of local treatment of mucoepidermoid carcinoma, granular cell myoblastoma and fibrosarcoma that were intraluminal $[33,35]$.

The use of photodynamic therapy for treating early stage superficial squamous cell cancer in the central airways has increased awareness of the curative potential of local treatment $[8,16,20]$. Although this may sound incorrect from the perspective of histology classification, the accepted standard strategy of surgical resection has to be seen in the proper perspective, especially when dealing with severe comorbidities. The assumption that delayed surgery will quickly lead to the development of metastases cannot be defended based on current knowledge of the chronic process of carcinogenesis and tumour biology. Therefore, the interventional bronchoscopist has to be fully aware of the potentials and limitations of minimally invasive approaches to intervene in a timely manner.

\section{Malignant tumours in the central airways}

The knowledge that squamous cell cancer can proximally extend, precluding a radical resection, has led to the application of photodynamic therapy as the initial treatment to enable less extensive resection $[19,36,37]$. A combined approach may increase the option for radical resection with preservation of normal lung parenchyma for better QoL.

\section{Nonsurgical candidates}

Patients with occult squamous cell cancers, regarded as medically unfit, have been primarily treated with various intraluminal techniques. Long-term survival has been shown. This indicates the curative potential of intraluminal therapy. Higher response rates were correlated with tumour dimension, indicating the paramount importance of early detection and accurate staging [16, 20, 32]. Current abilities for accurate TNM staging in the early event of carcinogenesis, together with local intervention (e.g. bronchoscopic treatment), will be implemented increasingly upfront as an alternative to immediate surgical approach at the earliest disease stage $[8,10,13,20-22]$.
Interventional pulmonology techniques, such as early detection and staging, e.g. autofluorescence imaging, electromagnetic navigation, virtual bronchoscopy, endobronchial ultrasound with transbronchial needle aspiration and optical biopsy techniques, will be increasingly integrated in this early interventional strategy [26, 27, 38, 39]. These important developments cannot be seen separately from the perspective of treatment only.

The recognition that carcinoma in situ and possibly atypical alveolar (adenomatous) hyperplasia may be regarded as endsteps in carcinogenesis does require a comprehensive strategy within the field of interventional pulmonology and oncology [40]. Interventional pulmonology together with, for example, conformal stereotactic radiation [41], radiofrequency ablation [42] or transthoracic photodynamic therapy (PDT) [43], will provide a vast array of local treatment alternatives that are minimally invasive and should be diligently investigated. The issue of overdiagnosis and treatment of pseudo-diseases justifies an interventional approach fraught with lower morbidity and mortality for potentially malignant clonal cells that are being detected in increasing numbers [29-31].

The following three sections describe four endoscopic techniques that are used with palliative and curative intent. Their common feature is their immediate treatment effect, contrary to techniques such as cryotherapy, PDT and brachytherpay with delayed effect, which will be described in another article of this review series.

\section{LASER RESECTION}

\section{Equipment and technical background}

Laser resection is the application of laser energy delivered via rigid and/or flexible bronchoscopes in order to manage (palliate or cure) different endobronchial lesions.

The word "laser" is an acronym for "light amplification of stimulated emission of radiation". Laser lights that can be delivered through optical fibres are suitable for bronchoscopic applications. Three main characteristics determine the suitability of a particular laser for therapeutic bronchoscopy: 1) power density rating; 2) ratio of absorption and scattering coefficients in soft tissue; and 3) the delivery system. Power density depends on laser technology and on factors such as target tissue and exposure time. By determining the volume of tissue that is heated, absorption and scattering make the difference between cutting and haemostasis. Lasers with high absorption coefficients and high scattering coefficients are good coagulators. The different types of laser and their characteristics are listed in table 1 and figure 2 . The neodynium:yttrium aluminium garnet (Nd-YAG) equipment is the most widely used type of laser for bronchoscopic interventions because it has sufficient power to vaporise tissues and produces an excellent coagulation effect. Its wavelength is $1,064 \mathrm{~nm}$, which is in the invisible range; therefore, it needs a pilot light usually in the red colour range. Both contact and noncontact probes are available. In the noncontact mode, the tip of the probe is held at $\sim 1 \mathrm{~cm}$ proximal to the target. An initial power setting of $20-40$ Watts with a pulse duration of $0.5-1 \mathrm{~s}$ represents a safe initial setting to obtain devascularisation. To carbonise tissue, the tip of the probe is either moved closer to the target at $\sim 3 \mathrm{~mm}$ or several pulses are applied at 
the same location. When treating obstructing lesions of the central airways, the aim is to devascularise the tumour and subsequently core out the bulk of the tumour with the tip of the rigid bronchoscope. When working with a flexible bronchoscope, the lesion is either devascularised or carbonised and the remaining tissue removed by forceps, or the whole lesion is vaporised. Both rigid and flexible techniques are used successfully [44-47]. Protective eyewear is mandatory when the laser beam is activated.

The carbon dioxide $\left(\mathrm{CO}_{2}\right)$ laser with a wavelength of $10.600 \mathrm{~nm}$ is an excellent cutting tool with an almost scalpellike precision. However, its application in the tracheobronchial tree has been limited by its poor coagulating properties and,

\section{TABLE 1 Laser equipment for bronchoscopic applications}

\begin{tabular}{lccc} 
Type of laser & Wavelength $\mathbf{n m}$ & \multicolumn{2}{c}{ Biological effects } \\
\cline { 3 - 4 } & & Vaporisation & Coagulation \\
\hline Nd-YAG & 1064 & ++ & ++ \\
$\mathbf{C O}_{2}$ & 10600 & $+{ }^{\#}$ & - \\
Argon & $488-514$ & - & ++ \\
Dye & $360-700$ & Activate photochemicals \\
Diode & 810 & + & ++ \\
Excimer & $193-351$ & Tissue destruction by mechanical \\
YAP-Nd & 1340 & \multicolumn{2}{c}{ effect } \\
\hline
\end{tabular}

Nd-YAG: neodymium:yttrium aluminium garnet; $\mathrm{CO}_{2}$ : carbon dioxide; YAP-Nd yttrium aluminium pevroskite:neodymium. +: moderately good; ++: good; +++ excellent; ?: doubful effect. ${ }^{*}$ : precise cutting effect.

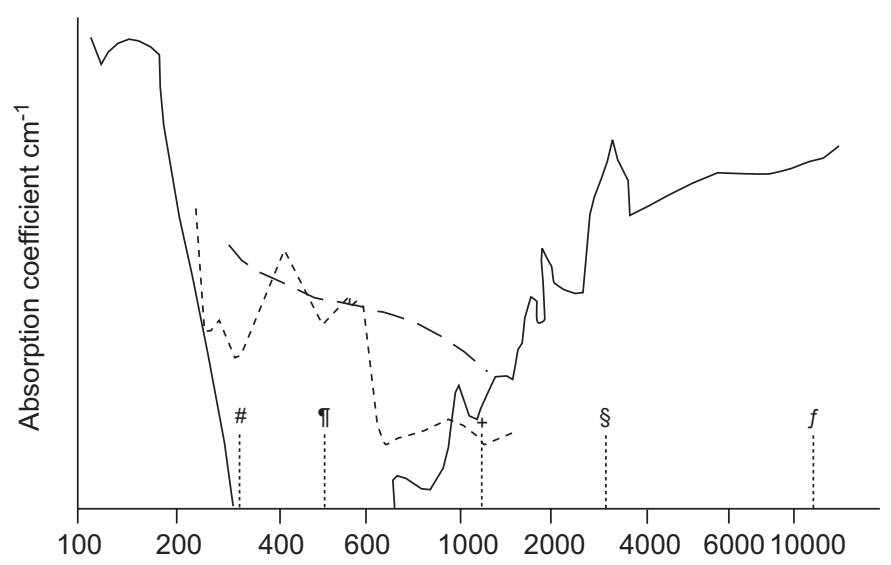

Wavelength $\mathrm{nm}$

FIGURE 2. Absorption of the three main chromophores. The physics of laser tissue interactions, with regard to the different wavelengths used by the different specialties, can be understood from the absorbance characteristics of wavelength versus oxyhaemoglobin $\left(\mathrm{HbO}_{2}\right)$ - or water $\left(\mathrm{H}_{2} \mathrm{O}\right)$-containing tissue as light photons are scattered, absorbed and reflected differently depending on the biocomponents in the target tissue. ——: $\mathrm{H}_{2} \mathrm{O}$; ----: $\mathrm{HbO}_{2}$; - - -: melanin. ${ }^{\#}$ : XeCl; " : potassium titanyl phosphate; ${ }^{+}$: neodymium:yttrium aluminium garnet; ${ }^{\text {s: }}$ : erbium:yttrium aluminium garnet; ${ }^{f}$ : carbon dioxide. $\cdots$ : wavelengths of the respective lasers indicating the cut-off values. more importantly, by the need of a cumbersome articulated arm delivery system which precludes it use distal to the main carina. The $\mathrm{CO}_{2}$ laser is quite popular with ear, nose and throat (ENT) surgeons for the upper respiratory tract. A detailed description of the other available lasers listed in table 1 is beyond the scope of this article.

Laser resection delivered via a rigid or flexible bronchoscope requires anaesthesia (topical anaesthesia with or without conscious sedation, or general anaesthesia). Procedures performed with the rigid scope always require general anaesthesia.

\section{Clinical experience and results}

For nearly $80 \mathrm{yrs}$ in the history of bronchology, therapeutic interventions were limited to foreign body removal and suctioning of airway secretions. In 1976, LAFORET et al. [48] reported the first applications of laser for the management of airway tumours. TOTY et al. [49], DUMON et al. [50], and CAVALIERE and colleagues [51,52] published their experiences with the application of Nd-YAG laser in endoscopic tracheobronchial surgery, which became the most frequently used nonsurgical technique in the management of malignant, benign and miscellaneous endobronchial disorders $[3,53]$.

The main indication for laser bronchoscopy comprises obstructive lesions of the trachea (fig. 3), the left and right main bronchi, the bronchus intermedius, and the lobar orifices that compromise ventilation and produce severe symptoms (including dyspnoea, stridor, intractable cough, and haemoptysis; see table 2). Laser treatment of obstructions of segmental bronchi does not improve ventilation significantly. The most frequent indication is inoperable lung cancer with endobronchial manifestations. The main goal of the intervention is palliation. In most cases, laser bronchoscopy is combined with other treatment modalities, i.e. stenting, external beam irradiation and brachytherapy.

The only absolute contraindication is external compression. There are relative contraindications, such as hypoxaemia, broncho-oesophageal fistula and coagulopathy. Complications of laser bronchoscopy include hypoxaemia, bleeding, perforation, fistula formation and fire. The risk of fire necessitates a strict limitation of the inspired oxygen concentration to $\leqslant 40 \%$.

The channel of the rigid bronchoscope is large enough to simultaneously allow ventilation, passage of different laser fibres and a suction tube. In addition to photocoagulation,
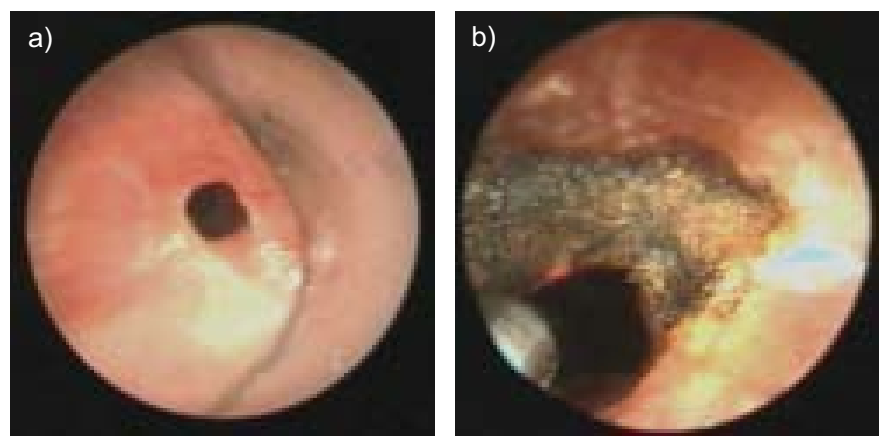

FIGURE 3. Post-intubation web-like tracheal stenosis a) before and b) after laser resection. 


$\begin{array}{ll}\text { TABLE } 2 \text { Indications for laser resection and electrocautery } \\ \text { Malignant disorders } & \text { Primary lung cancer } \\ & \text { Endobronchial metastasis (from breast, colon, kidney, } \\ & \text { thyroid gland, oesophagus) } \\ \text { In situ carcinoma" } & \text { Typical carcinoid" } \\ \text { Benign tumours } & \text { Papilloma, fibroma, lipoma, hamartochondroma, } \\ \text { Stenoses } & \text { leiomyoma } \\ & \text { Due to the following: } \\ & \text { Anastomosis (lung transplantation, surgical resection) } \\ & \text { Intubation } \\ & \text { Tracheotomy, tracheostomy } \\ & \text { Tuberculosis } \\ & \text { Sarcoidosis } \\ \text { Wegener's granulomatosis } & \text { Trauma } \\ \text { Inhalation injury } \\ \text { Radiation therapy } \\ \text { Granulation tissue } \\ \text { Reduction of bleeding } \\ \text { Amyloidosis } \\ \text { Endometriosis } \\ \text { Closure of oesophago-bronchial fistulas } \\ \text { Foreign body removal (lithotripsy) } \\ \text { Miscellaneous }\end{array}$

\#: Endobronchial obstruction in the central airways; " intended to be curative.

mechanical dilation with rigid tubes of increasing diameter can also be performed. The rigid technique is clearly favoured for speed and safety by bronchoscopists skilled in both techniques $[50,54,55]$.

In the treatment of early stage lung cancer, the flexible bronchoscope is comparable to the rigid method. A more indepth discussion on the endobronchial managemant of early stage lung cancer is given in the sections: Electrocautery and argon plasma coagulation and The clinical perspective of intraluminal techniques and the issue of costs.

Data of an unpublished survey in Europe suggested that the majority of these procedures should be performed in pulmonology referral centres where specialised teams with adequate experience in performing these interventions are available.

\section{ELECTROCAUTERY AND ARGON PLASMA COAGULATION}

The use of electrical current for tissue heating is called electrocautery or diathermy. Due to a voltage difference between probe and target tissue, electrons will flow and current density can be controlled using probes that conduct the electrons towards the target [56]. Electrons will generate heat for tissue coagulation due to the higher resistance of the target tissue. Argon plasma coagulation (APC) uses ionised argon gas jet flow (=plasma) to conduct electrons allowing a noncontact mode of treatment (lightning effect) [57].

\section{Equipment and technical background}

The high-frequency electrical generator is a standard instrument in every hospital to generate alternating current that prevents neural and muscular response. A plate is attached to the patient to ground electrons. APC has been popular in gastrointestinal endoscopy for superficial coagulation of large mucosal surfaces. The argon gas quite flexibly flows around bends and corners. Coagulated tissue has a higher resistance that automatically drives the argon gas flow away to nearby untreated tissue. Therefore, APC is suitable for treating bronchial segments which take off at an acute angle from the major airways, such as apical and posterior segments of the upper lobes or the apical lower lobe segments. This has an advantage over laser bundles, which always leave the probe in a straightforward way.

Various probes are available to perform controlled conductance of electrons, including: biopsy forceps, knives, blunt probes, suction rods, cutting loops, etc. Each probe can be chosen to match the personal expertise and needs. Current density is the issue to be considered, as the size of the probe functions as the focusing point for electrons. Therefore, ultimate tissue effect depends on voltage difference between probe and tissue (i.e. the Wattage setting), the surface area of contact (e.g. a smaller probe will increase current density), the duration of energy application (i.e. the time duration electrons are allowed to pass) in the absence of leak (mucus, blood and conductance of metal part of the bronchoscope or other instruments). More importantly, an immediate effect really can be seen during electrocautery treatment, which corresponds well with the histological effect of coagulative necrosis [58].

The vast array of instruments (rigid or flexible), both for contact or noncontact mode, is appealing for every purpose as it matches personal expertise and need (fig. 4). Maintenance cost is low, re-usable applicators are cheap, while the principle is straightforward and easy to comprehend, especially in comparison to Nd-YAG laser which is the most popular technique in larger institutions [59-61]. The contact mode, i.e. palpation to coagulate tumour, is similar to Nd-YAG laser by

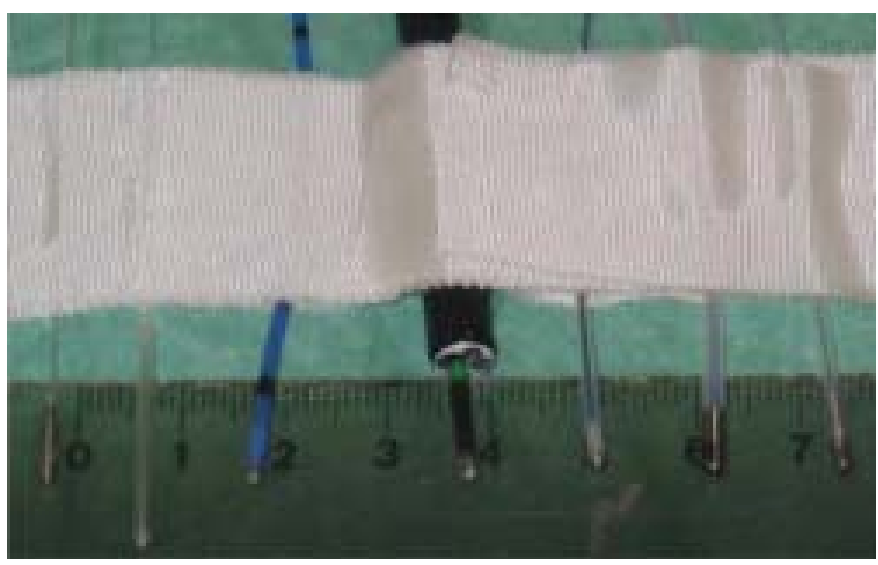

FIGURE 4. The various flexible applicators for local treatment using the fiberoptic bronchoscope. From left to right, photodynamic therapy (PDT) microlens fibre for surface illumination, PDT cylindrical-diffusor for intraluminal illumination, argon plasma catheter (blue) for noncontact mode diathermy coagulation, monopolar electrocautery probe for contact diathermy coagulation protruding out of the working channel of the broncho-videoscope, high dose rate brachytherapy catheter for intraluminal irradiation, cryotherapy probe and neodymium:yttrium aluminium garnet laser fibre. 
way of the sapphire probe, while the noncontact mode of APC is similar to the $\mathrm{CO}_{2}$ laser for achieving superficial coagulation.

Coagulation, cutting, fulguration, vaporisation and all combinations with mechanical debulking for quick airway recanalisation can be performed. Significant residual extraluminal stenosis or airway wall collapse can be managed by stent placement (see Stents section).

Arguments have been raised that, compared with Nd-YAG laser, the effect of electrocautery and APC are superficial. NdYAG laser is the most popular technique for coagulation due to its enormous heat sink effect, as photons of 1,064 nm deeply scatter causing profound tissue necrosis. In contrast, electrons do not scatter and dissipate into the deeper layers beneath the point of impact, leading to superficial necrosis similar to the $\mathrm{CO}_{2}$ laser for treating watery tissue.

Deep tissue coagulation may not always be preferable due to the vicinity of major vessels in the central airways in the changed anatomy following previous treatments (surgical resection, chemoradiotherapy). The importance of coagulation to minimise profuse bleeding prior to debulking is the accepted strategy in restoring the airway passage $[2,3]$.

Logistics for applying electrocautery and APC are simple (no goggles and coverage of reflecting surfaces) and the system runs on much less electrical energy. The ease of using the instrument and flexible applicators, in addition to the standard facility of the fiberoptic bronchoscope, is a great advantage (similar to the flexibility of a brachytherapy catheter versus the rigidity of microlens and cylindrical diffuser for PDT, cryoprobe and $\mathrm{Nd}-\mathrm{YAG}$ laser probe).

APC as a noncontact mode using an argon plasma jet also clears the pool of mucus and blood and conducts electrons around the corner. It allows spraying of larger surface areas to obtain homogeneous and superficial necrosis. Therefore, electrocautery and APC are elegant for treating early stage superficial squamous cell cancer known to be several cell layers thick, similar to using the $\mathrm{CO}_{2}$ laser or ultraviolet light illumination for PDT using Photofrin $\mathrm{II}_{\circledast}$ sensitisers (QLT pharmaceuticals, Vancouver, BC, Canada) [62].

\section{Clinical experience and results}

In 1985, HOOPER and JACKSON [59, 60] reported the use of electrocautery through the fiberoptic bronchoscope and its economic potential, but the popularity of Nd-YAG laser was overwhelming. The obvious advantages of electrocautery were not fully appreciated until cost-effectiveness became increasingly important $[61,62]$. In palliative interventional pulmonology, various available methods can currently be applied. Hot techniques achieve rapid haemostasis enabling mechanical debulking of obstruction tumours. This combination of techniques has become the cornerstone approach for immediate recanalisation $[2,3]$. Cryotherapy, brachytherapy and PDT are, therefore, less appropriate. Electrocautery and argon plasma coagulation are straightforward techniques enabling simpler clinical application than Nd-YAG laser [61-65]. Therefore, it is logical to extend the use of such a simple technique in treating local tumour growth for superficial early stage cancer in the central airways, as theoretical concepts behind early detection, staging and treatment are more important, rather than focusing on treatment technique per se as a separate entity $[9,13,17,18]$.

\section{Palliative intervention}

As described earlier, both intraluminal tumour growth and extraluminal compression of the central airways has to be anticipated in dealing with imminent suffocation. The advantages of hot techniques in combination with mechanical debulking and stenting have been addressed, in contrast to the delayed effect of cryotherapy, brachytherapy and PDT. From the clinical perspective, immediate symptomatic relief by tumour coagulation using electrocautery followed by mechanical debulking is straightforward and has been the accepted consensus strategy [2, 3, 61-66]. The effectiveness of stent placement for significant extraluminal disease has also been established. It is clear from the available data that electrocautery and argon plasma coagulation are superiorly costeffective compared with $\mathrm{Nd}-\mathrm{YAG}$ laser resection, i.e. allowing outpatient treatment under conscious sedation with better haemostasis, due to less complicated procedures and cheaper applicators. Success rate has been in the order of $70-80 \%$, which is comparable to other debulking techniques. However, for most indications it does not matter whether laser resection or electrocautery is used, as by and large both techniques achieve similar results and are to be considered competitive.

\section{Treatment with curative intent}

Arguments have been raised that the limited number of patients with occult cancer treated with various intraluminal bronchoscopic techniques does not justify their role. However, less extensive surgical resection, e.g. segmentectomy and surgical bronchoplasty, has been accepted as a legitimate approach for patients considered as being high risk surgical candidates with limited pulmonary function [5]. It is based on the recognition that minute early stage lesions within bronchoscopic visibility, according to strict bronchoscopic criteria (as proposed by IKEDA [67] in 1976), never have nodal disease. Meticulous histopathological studies from various Japanese centres and from the Mayo screening study confirmed the superficial nature of these lesions and the absence of the lymph nodes' metastasis [7, 68-70], while it has long been known that these lesions are only several millimetres thick. These data have increased the interest in applying PDT for treatment with curative intent and the move to early detection, localisation and application of methods for accurate staging prior to any treatment decision.

A vast array of early detection and staging methods are increasingly being investigated, including sputum cytometry, autofluorescence bronchoscopy, local staging with endobronchial ultrasound (EBUS), high-resolution computed tomography (HRCT), virtual bronchoscopy and ${ }^{18}$ F-fluoro-2-deoxy -D-glucose-positron emission tomography (FDG-PET) scan. Therefore, these investigational techniques, combined with minimally invasive intralesional treatment, can provide a costeffective early interventional management in the current screening area $[10-20,24,26,27,71]$. This has driven a paradigm shift towards early intervention, recognition of the individuals at the highest risk, biomolecular research, predictive algorithms for those at risk, and early interventional strategies, such as chemoprevention at the pre-neoplastic stage 
of early detected potentially malignant lesions [72-78]. The use of nonminimal invasive detection, staging and treatment methods for early parenchymal lesion is beyond the scope of the present article.

Lead time in a currently acknowledged chronic process of carcinogenesis does not seem to support immediate aggressive surgical management when dealing with subcentimetre early cancer lesions at the in situ stage. Carcinoma in situ and microinvasive squamous cell carcinoma are superficial and applying the rigid criteria of central type early cancer they are shown to be pTisN0 (pathologic stage, tumour in situ). At this stage there is a sufficient time interval that allows delayed surgical resection, which stresses the fact that current detection methods are able to localise central lesions in the clonal preneoplastic stage containing only 90,000 cells [79]. This opens new avenues in exploiting the potential of the fibreoptic bronchoscope and catheter-based techniques for early intervention (fig. 5; table 3 [80-84]). Guidelines for treating early lesions have been published [18, 74].
PDT is the most popular approach in treating early cancer lesions; however, the arguments regarding early treatment are primarily based on proper staging rather than treatment technique. The issue of alternative nonsurgical early intervention should be based on sound oncological considerations, including the analysis of tumour behaviour, cost-effectiveness and QoL [21, 22]. Early cancer lesions not involving lymph nodes are amenable for local therapy, thus, it is important to accurately stage local tumour growth. The role of autofluorescence bronchoscopy, EBUS, HRCT, FDG-PET scan and various treatments have been addressed before. Current data show that each IBT technique can eradicate $\sim 1 \mathrm{~cm}^{2} \leqslant 3 \mathrm{~mm}$ tumour volume with distinct distal tumour margin, as indicated from PDT data from various Japanese institutions $[16,20]$. Success rates have been in the $90-100 \%$ range, translating itself to local cure due to the reported (very long) follow-up time of $>5$ yrs. Tumour growth in the deeper layers and nodal disease are off limits for any local treatment. The cutting edge of the scalpel should be clearly indicated and compared with the cutting edge of IBT for local treatment that
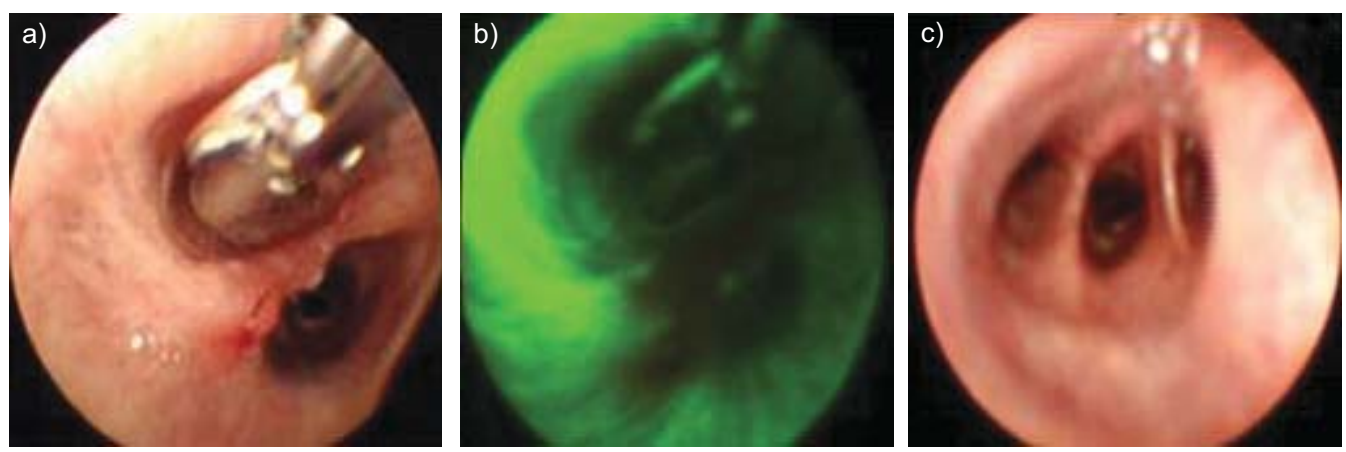

d)

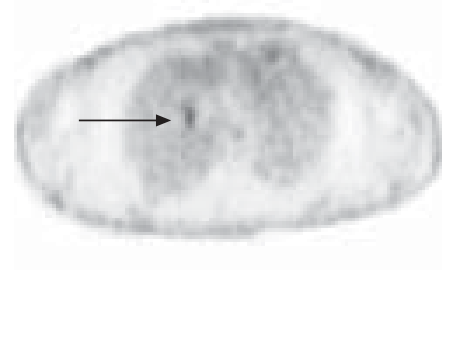

FIGURE 5. a) Microinvasive squamous cell cancer of the middle lobe carina $\left({ }^{18} \mathrm{~F}\right.$-fluoro-2-deoxy-D-glucose-positron emission tomography (FGD-PET) Scan tumourpositive lesion; d) with an estimated surface area of $\leqslant 3 \mathrm{~mm}^{2}$ prior to biopsy (indicated by arrow). The corresponding autofluorescence image (b) shows the size of the flexible biopsy forceps with open jaws, and the image of distal intermediate bronchus (c) shows some scarring of the previously treated microinvasive carcinoma of the carina of the superior segment of the right lower lobe (RB6). Complete tumour eradication being FDG-PET scan negative, 3 yrs post-electrocautery.

\begin{tabular}{|c|c|c|c|c|}
\hline First author [Ref.] & Methods & Patients n (lesions n) & Response & Survival months \\
\hline Cortese $[8]$ & PDT (Photofrin $\|_{\circledast}$ ) & 21 (23 resectable) & Nine patients (43\%) spared from surgery & $>24$ \\
\hline Hayata [16] & PDT (HpD) & (123) & $\begin{array}{l}\mathrm{CR} 93 \% \text { if }<1 \mathrm{~cm} \\
\mathrm{CR} 45 \% \text { if }>1 \mathrm{~cm}\end{array}$ & $<60$ \\
\hline AwADH $[81]$ & PDT (5-ALA) & 6 & CR 5/6 (83\%) & NA \\
\hline КАТО [83] & PDT (NPe-6) & $35(39)$ & CR $83 \%(84.6 \%)$ & NA \\
\hline MARSIGLIA [84] & HDR brachytherapy & 34 & Local control $85 \%$ & $\begin{array}{l}\text { Median } 24 \\
\text { Survival } 78 \%\end{array}$ \\
\hline DEYGAS [82] & Cryotherapy & 35 & CR $32 / 35$ (91\%) & $20 \%$ failure $>48$ \\
\hline VAN BOXEM [17] & Electrocautery & $13(15)$ & CR $80 \%, 10$ patients, 12 lesions & $16-43$ \\
\hline
\end{tabular}

PDT: photodynamic therapy; HpD: haematoporphyrin derivative; CR: complete response (radiographically occult cancers with negative histology/cytology at follow-up and normal radiological examinations); m-THPC: meta-(tetrahydroxyphenyl)chlorin; ALA: 5-aminolevulinic acid; NA: not available; NPe-6: mono-L-aspartyl chlorine 6; HDR: high dose rate. 
is more superficial, but less invasive and superiorly costeffective. New imaging facilities, e.g. automated sputum cytometry, optical coherence tomography, confocal endoscopy, Raman near infrared spectroscopy below the threshold of the conventional bronchoscope and microscopic examination are currently utilised for early detection and to stage precursor lesions more accurately [26, 27].

\section{STENTS}

Stents are devices for the internal splinting of luminal structures. In the airways, four major indications have been established: 1) counteracting extrinsic compression from tumours or lymphnodes; 2) stabilising airway patency after endoscopic removal of intraluminally growing cancer; 3) sealing malignant fistulas, e.g. stump dehiscences or fistulas between trachea and oesophagus; and 4) treating benign strictures.

\section{Equipment and technical background}

The first stents that were widely used were the T-tubes developed by MONTGOMERY [85]. Though they require a tracheostomy, these silicone stents are still widely used by ENT surgeons and they are considered to be the safest approach in cases of very high tracheal stenoses. WESTABY et al. [86] modified this stent and designed a T-Y prosthesis, which enabled splinting of the carinal region. Using the same tissue-friendly silicone material, DUMON [87] developed the first stents that could be inserted through a bronchoscope without a tracheostomy. In retrospect, Dumon's achievement gave the discipline of interventional bronchology very important momentum. Suddenly, pulmonologists could approach and treat conditions that had formerly been considered either completely untreatable or treatable only by extensive surgical procedures. At present, Dumon stents are still the most widely used worldwide [88]. These versatile silicone stents are available in different lengths and diameters for tracheal and bronchial stenoses for adults and children (Novatech SA, La Ciotat, France). Usually, Dumon stents are placed using rigid bronchoscopy under general anaesthesia, which limits their use to centres where rigid bronchoscopy is practiced. A few years after the Dumon stent, other polymer stents were developed and commercialised (fig. 6). Conformité Européene [European Conformity] (CE) Mark and Food and Drug Administration (FDA) approval has been given to the Polyflex ${ }^{\mathrm{TM}}$ stent (Rüsch, Kernen, Germany). Its wall thickness is lower providing a bigger inner lumen than the Dumon stent [89]. In contrast to Dumon stents, normal Polyflex ${ }^{\mathrm{TM}}$ stents do

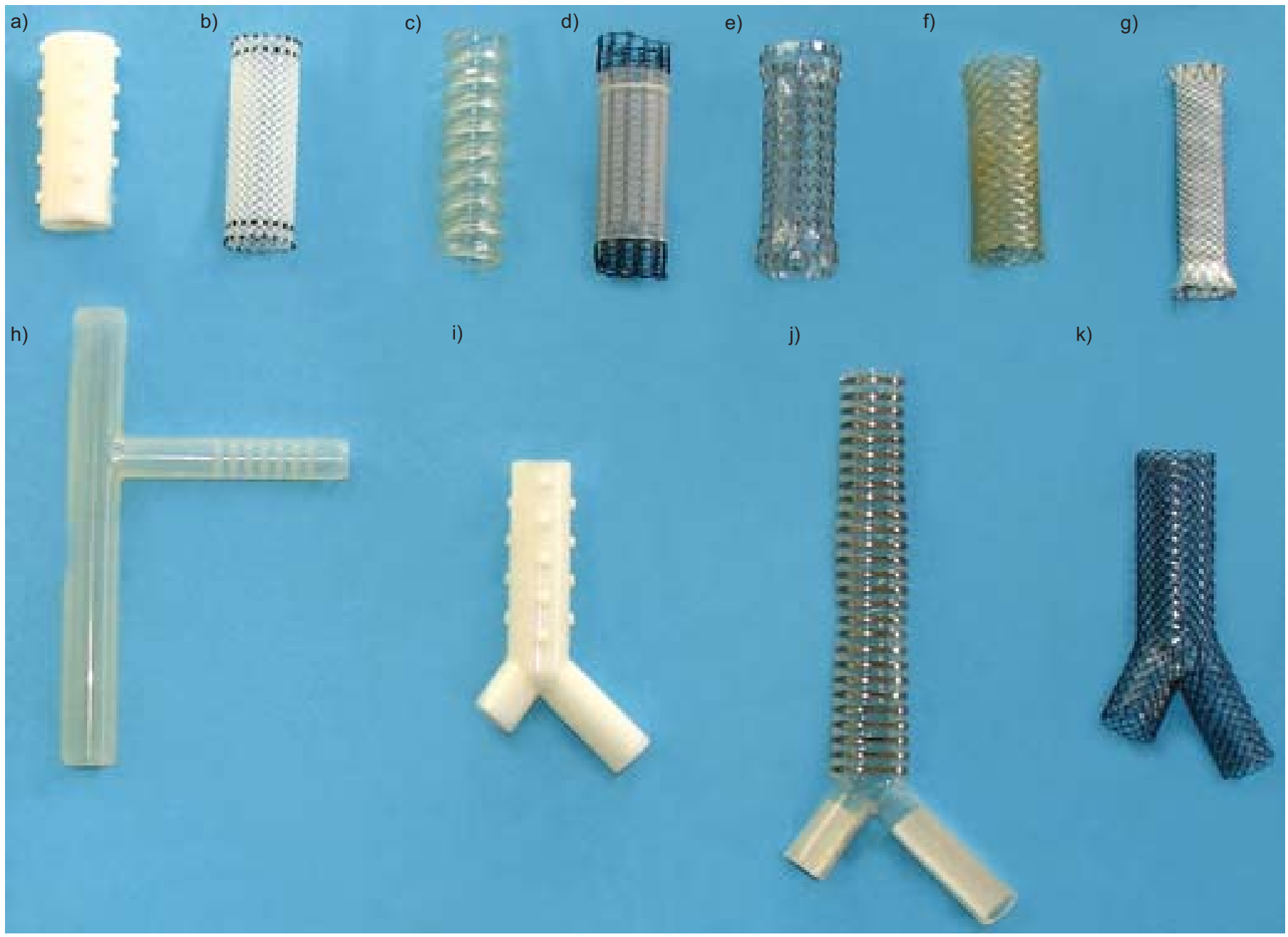

FIGURE 6. Currently available stents with a Conformité Européene Mark: a) Dumon stent; b) Polyflex(iil stent; c) Noppen stent; d) covered Ultraflex(ii stent; e) Alveolus Areo stent; f) Wallstent; g) Mandel and Rupp bronchial stent; h) Montgomery t-stent; i) bifurcated Dumon stent; j) Dynamic stent; and k) Micro-tech bifurcation stent. 
not have studs outside, a fact that increases the risk of migration. BOLLIGER et al. [90] recently reported on a modified Polyflex ${ }^{\mathrm{TM}}$ stent with studs on the outer surface that seems to have solved this problem. The third polymer stent that is available in Europe is the Tygon stent developed by NOPPEN et al. [91] (Reynder Medical Supply, Lennik, Belgium). It is less expensive but seems to be equally effective as the Dumon stent. All polymer prostheses are deployed out of a rigid or semi-rigid tube, requiring general anaesthesia. This disadvantage is outweighed by the fact that these stents can be easily repositioned, removed or replaced at any time.

For longer stenoses and obstructions involving the carinal region, Y-shaped stents are available. The Dynamic stent developed by FreITAG et al. [92] (Boston Scientific Corporation, Natlick, MA, USA) is a hybrid stent made from silicone with horseshoe-shaped steel clasps. In their original form, and with individual modifications, they have been successfully used for the sealing of oesophagotracheal fistulas and stump fistulas $[92,93]$. Other bifurcated prostheses are available from the Hood Company (Hood Laboratories, Decature, GA, USA) and as part of the Dumon set.

The other family of stents is made from metals, such as steel, nitinol and phynox. At first sight, there are many advantages to metal constructions over polymer prostheses. In general, the walls of metal stents can be thinner due to the far higher elastic modulus of metals compared with rubber materials. If a smaller airway is splinted by a stent with a wall thickness of $2 \mathrm{~mm}$ on both sides, the internal luminal gain is not significant. In addition, functionality requires a substantial length of these stents [94]. Thus, placing silicone stents into lobar bronchi is either impossible or does not make sense. While former stents, such as the Palmaz steel stent had required some kind of dilatation, e.g. with a balloon, all modern metal stents with $\mathrm{CE}$ marks and FDA approval for tracheobronchial use are selfexpanding. Early stents were uncovered but the high incidence of complications convinced most practicing physicians, and the industry, that covered metal stents are advantageous [95-97]. The Wallstents currently marketed (Boston Scientific), Ultraflex stents (Boston Scientific) and Alveolus stents (Alveolus Inc, Charlotte, NC, USA; fig. 7) have unique shapes and vary in their biomechanical behaviour, but they are all covered by thin polymer membranes. According to sales advisors, self-expanding covered metal stents already have the largest market share. The use of uncovered stents is now limited [98]. All these self-expanding metal stents can be inserted with flexible instruments under local anaesthesia.

\section{Clinical experience and results}

There are a huge number of case reports and small series in the published literature proving the feasibility of stent placement, acceptance and tolerance. Considering the popularity of stent placement, there are very few multicentre studies and not a single randomised study comparing treated and untreated patients or stent type A versus stent type B.

Stents are indicated if the airways are considerably compressed from the outside by malignancies. There is no clear advantage of any type of stent [88, 89, 91, 92, 95, 98-104]. Stents can be used temporarily $[92,105]$ in a multimodality concept of cancer care and as a last palliative measure for end-stage
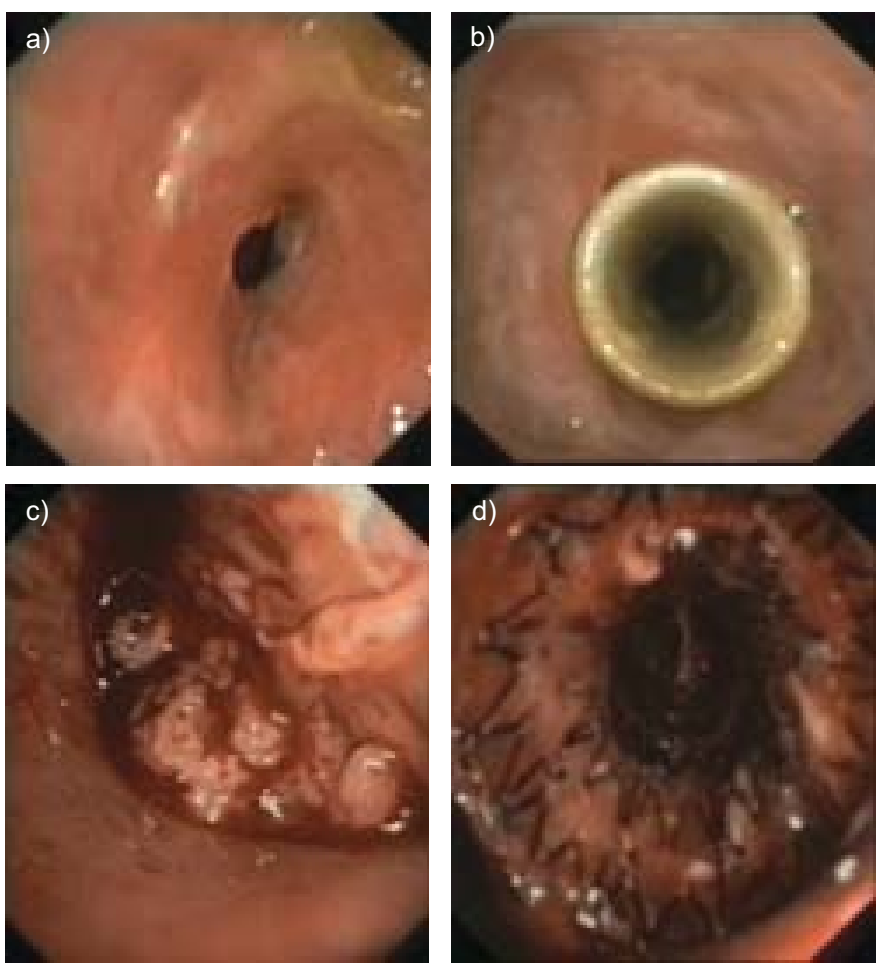

FIGURE 7. a) Inoperable benign stricture of a high tracheal stenosis and b) the same bronchoscopic image 4 yrs after insertion of a tracheal Dumon stent (no complications occurred during these 48 months). c) Malignant tumour obstructing the left lower lobe; d) following laser removal of the exophytic tumour tissue, a completely covered Alveolus Aero stent has been inserted.

cancer patients $[106,107]$. The efficacy regarding functional improvement and QoL appears to be proven [90, 108]. Newer investigations indicate that the problem is more complex than originally thought. MrYAZAWA et al. [109] recently pointed out that the exact choke point has to be determined and exact stent positioning is necessary to guarantee functional benefit. They used EBUS in their decision algorithm. The expansion force of a stent that is necessary to cope with a malignant compression still remains unclear [96]. It is likely that stents with identical sizes and shapes but different hoop stresses (recoil) for different biomechanical conditions will be available in the near future. The industry will provide measuring devices to help physicians decide which stent should be used for a given condition. From a biomechanical point of view, the largest possible stent should be used. In most cases of malignant compromise of the central airways, this requires other interventional methods, such as laser desobliteration or balloon dilatation, prior to stent placement. Considering the possible complications and the high cost of the prostheses, stents should only be placed if a patient can truly benefit from it.

Stents can help to seal fistulas between the respiratory tract and the aerodigestive tract $[93,110]$. Perforation and migration of oesophageal stents is prevented by tracheal stents. For large oesophagotracheal fistulas, double stenting seems to be superior over single stenting of either the oesophagus or the trachea. Stump fistulas or dehiscences have been treated by offthe-shelf or modified stents. They have been used to bridge the gap between or complementing surgery [96, 111, 112]. In any 
case, a multidisciplinary approach, mostly combined with a thoracostoma, is required for clinical success.

Less clear are the indications for benign strictures. In cases of tracheal stenoses, surgeons argue that sleeve resection is the only solution and that stent placement does more harm than good. Pulmonologists usually answer with a stent case showing how they saved a patient's life who had suffered from surgical complications. In any meeting, this topic guarantees an emotional debate between interventional pulmonologists and surgeons. Every major institution has its own clinical pathway [113]. The quality of the tracheal surgeon is probably the most important factor. The algorithm developed by BRICHET et al. [114] is the only one based on a clear study design. If stents improve (less tissue-hostile), these algorithms will need to be updated. Eventually, the value of stents for certain indications will only be accepted by all when the procedures have passed the test of time. Meanwhile, airway stents are considered feasible and cost-effective for the treatment of airway compressions from benign thyroid diseases [115] and stent placement into post-operative strictures, e.g. in transplantation anastomoses, has become an accepted treatment modality [116].

Following a lot of hype in the late 1990s, a growing number of articles deal with stent-associated complications. Retained secretions, colonisation of stent material, migration, stent fractures and development of granulation tissue are frequent findings [88, 97, 117-123]. Migration rates vary from $20-50 \%$. Obviously metal stents have a higher rate of migration than silastic stents. Migration occurs more often in benign strictures than in malignant diseases; in malacic segments they will certainly move unless a Y-stent is used where anchorage is guaranteed by the bronchial legs. Biomechanically, it is challenging to develop a stent that should not migrate, but at the same time should be easy to remove. Stents impair mucus clearance and many stent patients require bronchoscopic suctioning. Accumulation of secretions can be considered a slightly annoying problem or a severe complication. Though colonisation and formation of biofilms in the prostheses does not necessarily mean that there is an infection, halitosis can be very compromising for a patient. Granulation tissue formation at the edges of stents, even months after they have been inserted, can significantly narrow down the internal lumen. This can gradually increase the work of breathing to a degree similar to where the patient had been before the stent was placed. Removal of these granulomas is not easy as they tend to bleed heavily and the use of techniques, such as laser resection, is relatively contraindicated because the stent material is inflammable [124], especially with an inspiratory oxygen fraction exceeding $40 \%$.

It is agreed by all experts in the field that the ideal stent still has to be developed. In the area of stents that could be inserted to keep the patient alive, the time has come to develop stents that adequately address the QoL issues. Newer materials, a better understanding of airway biomechanics [109] and other approaches, such as bioabsorbable stents [125], will lead to improvements.

The deployment system of stents has improved over recent years making it easier for less experienced endoscopists to place stents. General recommendations by most societies and opinion leaders still include statements such as "rigid bronchoscopy should be available" or "expertise and equipment should be available to deal with complications". However, these statements are only fair if enough training opportunities for interventional bronchology (including the use of rigid instruments) are provided in the reality. Unless there is a fair reimbursement practice, European hospitals will not maintain departments of interventional bronchoscopy. If a complex procedure, performed by a team of experienced endoscopists, anaesthesiologists and nurses, is not sufficiently paid for, patients will not receive optimal treatment but a quick and, most importantly, cheap fix of their problem. If societies do not succeed in providing enough training facilities and financial compensation, the industry has to come up with systems that combine ease of use with short- and long-term safety.

\section{THE CLINICAL PERSPECTIVE OF INTRALUMINAL TECHNIQUES AND THE ISSUE OF COSTS}

Facilities in larger institutions allow multidisciplinary use of more complex equipment for the different specialities. Several bronchoscopic treatment alternatives are currently available.

As success rate is primarily based on correct identification of subjects at risk and accurate staging, the implementation of simple nonsurgical interventions will be increasingly appreciated based on the issues of cost-effectiveness and QoL.

For quick palliation of end-stage lung cancer with major airways obstruction, bronchoscopic techniques, i.e. stenting for extraluminal stenosis, and hot techniques for tumour coagulation (laser resection, electrocautery, APC) with mechanical debulking have been firmly established in the current management of patients.

The impact of relatively low positive predictive values of many early screening strategies will generate many false positive results, as abnormalities found are mainly noncancerous. The potential of minimally invasive techniques to confirm or refute the presence of early cancer and its precursor lesions is, therefore, obvious.

For treatment with curative intent, diligent prospective studies are warranted to further explore the increasing potential of bronchoscopic and catheter-based technologies as less invasive and morbid early interventional modalities. Intralesional treatments, e.g. electrocautery and cryotherapy, are simple compared with laser resection, brachytherapy and PDT. Easy logistics and low maintenance costs are still very attractive even in a larger institution involved in a primary screening setting.

\section{FUTURE STRATEGIES}

Current interest in stage shift as the primary goal in a lung cancer screening setting poses a great challenge for its clinical management. Minimally invasive techniques already provide alternatives for patients who are medically unfit.

As the earliest stage of cancer, i.e. carcinoma in situ and alveolar adenomotaus hyperplasia, involves subcentimetre lesions, surgical intervention, as the gold standard, may become disproportionally invasive and costly. It may be rigidly stated that nonsurgical approaches are still inappropriate until data from phase III prospective trials are mature in 
showing similar efficacy to surgical resection. However, the following points need some consideration. 1) Alternative techniques for medically unfit patients are the only solution. Their inherent risk of dying from nonlung cancer-related causes and their exclusion from any screening programme justify wider implementation of minimally invasive techniques to preserve quality of life in the cohorts suffering from smoking-related diseases. 2) For individuals with resectable lesions, lead time in carcinogenesis increases the possibly negative impact of overdiagnosis. The low positive predictive value of current diagnostic algorithms, such as sputum cytology and low-dose spiral computed tomography, despite the additional use of the ${ }^{18} \mathrm{~F}$-fluoro-2-deoxy-D-glucose-positron emission tomography scan, still requires tissue biopsy. The preference for a minimally invasive manner prior to any treatment commencement is obvious. 3) Follow-up data of primary screening trials show that more early stage cancers are being detected. However, downstream morbidities, mortalities and prolonged emotional insecurity are enormous. If only noninvasive imaging techniques are used, surgical intervention for benign diseases will remain problematic. The importance of implementing new techniques for tissue biopsy and providing alternative strategies, which are less invasive, is of great interest. 4) Increasing ability to accurately stage and treat early cancer lesions in a non- and minimally invasive manner, together with long-term survival outcome data (e.g. central early stage lesion, pure ground-glass opacity peripheral lesions, tumour and lymph nodes' negative ${ }^{18} \mathrm{~F}$-fluoro-2deoxy-D-glucose-positron emission tomography microinvasive cancer), seem to indicate the potential of commencing less aggressive approaches rather than an immediate surgical approach. 5) Tumour biology is recognised as becoming an important factor that determines outcome even in subcentimetre lesions. Immediate invasive strategies cannot prevent the dismal outcome of interval cancers representing more malignant cohorts of tumours in the subjects at risk. 6) A randomised phase III study to prove similar efficacy of any local therapy cannot address the impact of overdiagnosis as screening may detect a significant number of cancer lesions that are clinically irrelevant. However, alternative approaches can significantly reduce downstream morbidities, mortalities and costs generated by any primary screening programme.

\section{REFERENCES}

1 Parkin DM, Pisani P, Ferlay J. Global cancer statistics. CA Cancer J Clin 1999; 49: 33-64.

2 Dumon JF, Shapshay S, Bourcereau J, et al. Principles for safety in application of neodymium-YAG laser in bronchology. Chest 1984; 86: 163-168.

3 Bolliger CT, Mathur PN, Beamis JF, et al. ERS/ATS statement on interventional pulmonology. European Respiratory Society/American Thoracic Society. Eur Respir J 2002; 19: 356-373.

4 Ginsberg RJ, Rubinstein LV. Randomized trial of lobectomy versus limited resection for T1 N0 non-small cell lung cancer. Lung Cancer Study Group. Ann Thorac Surg 1995; 60: 615-622.

5 Endo C, Sagawa M, Sato M, et al. What kind of hilar lung cancer can be a candidate for segmentectomy with curative intent? Retrospective clinicopathological study of completely resected roentgenographically occult bronchogenic squamous cell carcinoma. Lung Cancer 1998; 21: 93-99.

6 Suzuki K. Thoracic Surgery Division, National Cancer Center Hospital, Japan. www.ncc.go.jp/en/ncch/ annrep/2002/thoracic_surgery.html. Date last updated: February 22, 2006. Date last accessed: March 22, 2006.

7 Woolner LB, Fontana RS, Cortese DA, et al. Roentgenographically occult lung cancer: pathologic findings and frequency of multicentricity during a 10-year period. Mayo Clin Proc 1984; 59: 453-466.

8 Cortese DA, Edell ES, Kinsey JH. Photodynamic therapy for early stage squamous cell carcinoma of the lung. Mayo Clin Proc 1997; 72: 595-602.

9 Pasic A, Postmus PE, Sutedja G. What is early lung cancer? A review of the literature. Lung Cancer 2004; 45: 267-277.

10 Lam S, MacAulay C, Hung J, LeRiche J, Profio AE, Palcic B. Detection of dysplasia and carcinoma in situ with a lung imaging fluorescence endoscope device. J Thorac Cardiovasc Surg 1993; 105: 1035-1040.

11 Venmans BJ, van Boxem TJ, Smit EF, Postmus PE, Sutedja G. Outcome of bronchial carcinoma in situ. Chest 2000; 117: 1572-1576.

12 Herder GJ, Breuer RH, Comans EF, et al. Positron emission tomography scans can detect radiographically occult lung cancer in the central airways. J Clin Oncol 2001; 19: 4271-4272.

13 Sutedja G, Codrington H, Risse EK, et al. Autofluorescence bronchoscopy improves staging of radiographically occult lung cancer and has an impact on therapeutic strategy. Chest 2001; 120: 1327-1332.

14 Miyazu Y, Miyazawa T, Kurimoto N, Iwamoto Y, Kanoh K, Kohno N. Endobronchial ultrasonography in the assessment of centrally located early-stage lung cancer before photodynamic therapy. Am J Respir Crit Care Med 2002; 165: 832-837.

15 Fujimura S, Sakurada A, Sagawa M, et al. A therapeutic approach to roentgenographically occult squamous cell carcinoma of the lung. Cancer 2000; 89: 2445-2448.

16 Hayata Y, Kato H, Furuse K, Kusunoki Y, Suzuki S, Mimura S. Photodynamic therapy of 169 early stage cancers of the lung and oesophagus: a Japanese multicentre study. Laser Med Sci 1996; 11: 255-259.

17 van Boxem TJ, Venmans BJ, Schramel FM, et al. Radiographically occult lung cancer treated with fibreoptic bronchoscopic electrocautery: a pilot study of a simple and inexpensive technique. Eur Respir J 1998; 11: 169-172.

18 Sutedja TG, van Boxem AJ, Postmus PE. The curative potential of intraluminal bronchoscopic treatment for early-stage non-small-cell lung cancer. Clin Lung Cancer 2001; 2: 264-270.

19 Kato H, Konaka C, Ono J. Preoperative laser photodynamic therapy in combination with operation in lung cancer. J Thorac Cardiovasc Surg 1985; 90: 420-429.

20 Furuse K, Fukuoka M, Kato H, et al. A prospective phase II study on photodynamic therapy with photofrin II for centrally located early-stage lung cancer. J Clin Oncol 1993; 11: 1852-1857. 
21 Kato H, Okunaka T, Tsuchida T, Shibuya H, Fujino S, Ogawa K. Analysis of the cost-effectiveness of photodynamic therapy in early stage lung cancer. Diagnostic and Therapeutic Endoscopy 1999; 6: 9-16.

22 Pasic A, Brokx HA, Noordegraaf AV, Paul RM, Postmus PE, Sutedja G. Cost-effectiveness of early intervention: comparison between intraluminal bronchoscopic treatment and surgical resection for T1N0 lung cancer patients. Respiration 2004; 71: 391-396.

23 Shinagawa N, Yamazaki K, Onodera Y, et al. CT-guided transbronchial biopsy using an ultrathin bronchoscope with virtual bronchoscopic navigation. Chest 2004; 125: 1138-1143.

24 Schwarz Y, Mehta AC, Ernst A, et al. Electromagnetic navigation during flexible bronchoscopy. Respiration 2003; 70: 516-522.

25 Gohagan J, Marcus P, Fagerstrom R, Pinsky P, Kramer B, Prorok P. Writing Committee, Lung Screening Study Research Group. Baseline findings of a randomized feasibility trial of lung cancer screening with spiral CT scan ws chest radiograph: the Lung Screening Study of the National Cancer Institute. Chest 2004; 126: 114-121.

26 McWilliams A, MacAulay C, Gazdar AF, Lam S. Innovative molecular and imaging approaches for the detection of lung cancer and its precursor lesions. Oncogene 2002; 21: 6949-6959.

27 Sutedja G. New techniques for early detection of lung cancer. Eur Respir J 2003; 21: Suppl. 39, 57s-66s.

28 Mahadevia PJ, Fleisher LA, Frick KD, Eng J, Goodman SN, Powe NR. Lung cancer screening with helical computed tomography in older adult smokers: a decision and cost-effectiveness analysis. JAMA 2003; 289: 313-322.

29 Black WC. Overdiagnosis: an underrecognized cause of confusion and harm in cancer screening. J Natl Cancer Inst 2000; 92: 1280-1282.

30 Marcus PM. Lung cancer screening: an update. J Clin Oncol 2001; 15: Suppl. 19, 83S-86S.

31 Marcus PM, Bergstrahl EJ, Fagerstrom RM, et al. Lung cancer mortality in the Mayo Lung Project: impact of extended follow-up. I Natl Cancer Inst 2000; 92: 1308-1316.

32 Vonk Noordegraaf A, Postmus PE, Sutedja G. Bronchoscopic treatment of patients with intraluminal microinvasive radiographically occult lung cancer not eligible for surgical resection: a follow-up study. Lung Cancer 2003; 39: 49-53.

33 Shah H, Garbe L, Nussbaum E, Dumon JF, Chiodera PL, Cavaliere S. Benign tumors of the tracheobronchial tree. Endoscopic characteristics and role of laser resection. Chest 1995; 107: 1744-1751.

34 Sutedja G, Schreurs AJ, Vanderschueren RG, Kwa B, vd Werf TS, Postmus PE. Bronchoscopic therapy in patients with intraluminal typical bronchial carcinoid. Chest 1995; 107: 556-558.

35 Kunst PW, Sutedja G, Golding RP, Risse E, Kardos G, Postmus PE. Unusual pulmonary lesions: a juvenile bronchopulmonary fibrosarcoma. J Clin Oncol 2002; 20: 2745-2751.
36 Sutedja G, Baris G, Zoetmulder F, van Zandwijk N. High dose rate brachytherapy improves resectability in squamous cell lung cancer. Chest 1992; 102: 308-309.

37 Schuurman B, Postmus PE, van Mourik JC, Risse EK, Sutedja G. Combined use of autofluorescence bronchoscopy and argon plasma coagulation enables less extensive resection of radiographically occult lung cancer. Respiration 2004; 71: 410-411.

38 Falcone F, Fois F, Grosso D. Endobronchial ultrasound. Respiration 2003; 70: 179-194.

39 Shirakawa T, Imamura F, Hamamoto J, et al. Usefulness of endobronchial ultrasonography for transbronchial lung biopsies of peripheral lung lesions. Respiration 2004; 71: 260-268.

40 Brambilla E, Travis WD, Colby TV, Corrin B, Shimosato Y. The new World Health Organization classification of lung tumours. Eur Respir J 2001; 18: 1059-1068.

41 Onishi H, Araki T, Shirato H, et al. Stereotactic hypofractionated high-dose irradiation for stage I nonsmall cell lung carcinoma: clinical outcomes in 245 subjects in a Japanese multiinstitutional study. Cancer 2004; 101: 1623-1631.

42 Jin GY, Lee JM, Lee YC, Han YM, Lim YS. Primary and secondary lung malignancies treated with percutaneous radiofrequency ablation: evaluation with follow-up helical CT. Am J Roentgenol 2004; 183: 1013-1020.

43 Okunaka $\mathrm{T}$, Kato $\mathrm{H}$, Tsutsui $\mathrm{H}$, Ishizumi $\mathrm{T}$, Ichinose $\mathrm{S}$, Kuroiwa Y. Photodynamic therapy for peripheral lung cancer. Lung Cancer 2004; 43: 77-82.

44 Cavaliere S, Dumon JF. Laser bronchoscopy. In: Bolliger CT, Mathur PN, eds. Interventional Bronchsocopy. Vol. 30. Basel, Karger, 2000; pp. 108-119.

45 Unger M. Bronchoscopic utilisation of the Nd:YAG laser for obstructing lesions of the trachea and bronchi. Surg Clin North Am 1984; 64: 931-938.

46 Mehta AC, Lee FY, Cordasco EM, Kirby T, de Boer G. Concentric tracheal and subglottic stenosis. Management using the Nd:YAG laser for mucosal sparing followed by gentle balloon dilatation. Chest 1993; 104: 673-677.

47 Lee P, Kupeli E, Mehta AC. Therapeutic bronchoscopy in lung cancer. Laser therapy, electrocautery, brachytherapy, stents, and photodynamic therapy. Clin Chest Med 2002; 23: 241-256.

48 Laforet EG, Berger RL, Vaughan CW. Carcinoma obstructing the trachea. Treatment by laser resection. $N$ Engl J Med 1976; 294: 941.

49 Toty L, Personne C, Colchen A, Vourch G. Bronchoscopic management of tracheal lesions using $\mathrm{Nd}$ :YAG laser. Thorax 1981; 36: 175-178.

50 Dumon JF, Rebound E, Garbe L, Aucomte F, Meric B. Treatment of tracheobronchial lesions by laser photoresection. Chest 1982; 81: 278-284.

51 Cavaliere S, Foccoli P, Farina P. Nd:YAG laser bronchoscopy: a 5-years experience with 1,396 applications in 1,000 patients. Chest 1988; 94: 15-21.

52 Cavaliere S, Foccoli P, Toninelli C. Endobronchial laser treatment. In: Strausz J, ed. Pulmonary Endoscopy. Eur Respir Mon 1998; 3: no. 9, pp. 49-64.

53 Ernst A, Gerard A. Silvestri GA, Johnstone D. Interventional pulmonary procedures guidelines from the 
American College of Chest Physicians. Chest 2003; 123: 1693-1717.

54 Cortese DA. Rigid versus flexible bronchoscope in laser bronchoscopy. J Bronchol 1994; 1: 72-75.

55 Dumon JF, Meric B, Bourcereau J, et al. Principles for safety in application of Nd:YAG laser in bronchology. Chest 1984; 86: 278-284.

56 Barlow DE. Endoscopic applications of electrosurgery: a review of basic principles. Gastrointest Endoscop 1982; 28: 73-76.

57 Grund KE, Storek D, Farin G. Endoscopic argon plasma coagulation (APC) first clinical experiences in flexible endoscopy. Endosc Surg Allied Technol 1994; 2: 42-46.

58 van Boxem TJ, Westerga J, Venmans BJ, Postmus PE, Sutedja G. Tissue effects of bronchoscopic electrocautery: bronchoscopic appearance and histologic changes of bronchial wall after electrocautery. Chest 2000; 117: 887-891.

59 Hooper RG, Jackson FN. Endobronchial electrocautery. Chest 1985; 87: 712-714.

60 Hooper RG. Electrocautery in endobronchial therapy. A letter to the editor. Chest 2000; 117: 1820.

61 Sutedja G, van Kralingen K, Schramel FM, Postmus PE. Fibreoptic bronchoscopic electrosurgery under local anaesthesia for rapid palliation in patients with central airway malignancies: a preliminary report. Thorax 1994; 49: 1243-1246.

62 van Boxem T, Muller $M$, Venmans B, Postmus $P$, Sutedja G. Nd-YAG laser vs bronchoscopic electrocautery for palliation of symptomatic airway obstruction: a costeffectiveness study. Chest 1999; 116: 1108-1112.

63 Reichle G, Freitag L, Kullmann HJ, Prenzel R, Macha HN, Farin G. Argon plasma coagulation in bronchology: a new method--alternative or complementary? Pneumologie 2000; 54: 508-516.

64 Coulter TD, Mehta AC. The heat is on: impact of endobronchial electrosurgery on the need for Nd-YAG laser photoresection. Chest 2000; 118: 516-521.

65 Morice RC, Ece T, Ece F, Keus L. Endobronchial argon plasma coagulation for treatment of hemoptysis and neoplastic airway obstruction. Chest 2001; 119: 781-787.

66 van Boxem AJ, Westerga J, Venmans BJ, Postmus PE, Sutedja G. Photodynamic therapy, Nd-YAG laser and electrocautery for treating early-stage intraluminal cancer: which to choose? Lung Cancer 2001; 31: 31-36.

67 Ikeda S. Atlas of early cancer of major bronchi. Tokyo, Igakushoin, 1976.

68 Usuda K, Saito Y, Nagamoto N, et al. Relation between bronchoscopic findings and tumor size of roentgenographically occult bronchogenic squamous cell carcinoma. J Thorac Cardiovasc Surg 1993; 106: 1098-1103.

69 Konaka C, Hirano T, Kato H, et al. Comparison of endoscopic features of early-stage squamous cell lung cancer and histological findings. Br J Cancer 1999; 80: 1435-1439.

70 Nagamoto N, Saito Y, Ohta S, et al. Relationship of lymph node metastasis to primary tumor size and microscopic appearance of roentgenographically occult lung cancer. Am J Surg Pathol 1989; 13: 1009-1013.

71 Sutedja G, Venmans BJ, Smit EF, Postmus PE. Fluorescence bronchoscopy for early detection of lung cancer: a clinical perspective. Lung Cancer 2001; 34: 157-168.

72 Petty TL. Screening strategies for early detection of lung cancer: the time is now. JAMA 2000; 284: 1977-1980.

73 Sutedja G, Postmus PE. Bronchoscopic treatment of lung tumors. Lung Cancer 1994; 11: 1-17.

74 Mathur PN, Edell E, Sutedja G, Vergnon JM. Treatment of early stage non-small cell lung cancer. American College of Chest Physicians. Chest 2003; 123: Suppl. 1, 176S-180S.

75 Uematsu M, Shioda A, Suda A, et al. Computed tomography-guided frameless stereotactic radiotherapy for stage I non-small cell lung cancer: a 5-year experience. Int J Radiat Oncol Biol Phys 2001; 51: 666-670.

76 Pasic A, Vonk-Noordegraaf A, Risse EK, Postmus PE, Sutedja G. Multiple suspicious lesions detected by autofluorescence bronchoscopy predict malignant development in the bronchial mucosa in high risk patients. Lung Cancer 2003; 41: 295-301.

77 Brambilla C, Fievet F, Jeanmart M, et al. Early detection of lung cancer: role of biomarkers. Eur Respir J 2003; 21: Suppl. 39, 36s-44s.

78 Lam S, MacAulay C, LeRiche JC, Gazdar AF. Key issues in lung cancer chemoprevention trials of new agents. Recent Results Cancer Res 2003; 163: 182-195.

79 Wistuba II, Lam S, Behrens C, et al. Molecular damage in the bronchial epithelium of current and former smokers. J Natl Cancer Inst 1997; 89: 1366-1373.

80 Grosjean P, Savary JF, Mizeret J, et al. Photodynamic therapy for cancer of the upper aerodigestive tract using tetra(m-hydroxyphenyl)chlorin. J Clin Laser Med Surg 1996; 14: 281-287.

81 Awadh N, MacAulay C, Lam S. Detection and treatment of superficial lung cancer by using Aminolevulinic Acid: a preliminary report. J Bronchology 1997; 4: 13-17.

82 Deygas N, Froudarakis M, Ozenne G, Vergnon JM. Cryotherapy in early superficial bronchogenic carcinoma. Chest 2001; 120: 26-31.

83 Kato H, Furukawa K, Sato M, et al. Phase II clinical study of photodynamic therapy using mono-L-aspartyl chlorin e6 and diode laser for early superficial squamous cell carcinoma of the lung. Lung Cancer 2003; 42: 103-111.

84 Marsiglia H, Baldeyrou P, Lartigau E, et al. High-doserate brachytherapy as sole modality for early-stage endobronchial carcinoma. Int J Radiat Oncol Biol Phys 2000; 47: 665-672.

85 Montgomery WW. T-tube tracheal stent. Arch Otolaryngol 1965; 82: 320-321.

86 Westaby S, Jackson JW, Pearson FG. A bifurcated silicone rubber stent for relief of tracheobronchial obstruction. J Thorac Cardiovasc Surg 1982; 83: 414-417.

87 Dumon JF. A dedicated tracheobronchial stent. Chest 1990; 97: 328-332.

88 Dumon JF, Cavaliere S, Diaz-Jimenez JP, et al. Seven-year experience with the Dumon prosthesis. J Bronchol 1996; 3: 6-10.

89 Wassermann K, Koch A, Müller-Ehmsen J, Reuter M, Michel O, Eckel HE. Clinical and laboratory evaluation of a thin-walled self-expanding tracheobronchial silicone stent: progress and pitfalls. J Thoracic Cardiocasc Surg 1997; 114: 527-543. 
90 Bolliger CT, Breitenbuecher A, Brutsche M, Heitz M, Stanzel F. Use of studded Polyflex stents in patients with neoplastic obstructions of the central airways. Respiration 2004; 71: 83-87.

91 Noppen M, Meysman M, Claes I, D'Haese J, Vincken W. Screw-thread vs Dumon endoprosthesis in the management of tracheal stenosis. Chest 1999; 115: 532-535.

92 Freitag L, Tekolf E, Stamatis G, Greschuchna D. Clinical evaluation of a new bifurcated dynamic airway stent. A five year experience in 135 patients. Thorac Cardiovasc Surgeon 1997; 45: 6-12.

93 Freitag L, Tekolf E, Steveling H, Donovan TJ, Stamatis G. Management of malignant esophago-tracheal fistulas with airway stenting and double stenting. Chest 1996; 110: 1155-1160.

94 Freitag L, Eicker K, Donovan TJ, Dimov D. Mechanical properties of airway stents. J Bronchology 1995; 2: 270-278.

95 Bolliger CT. Airway stents. Semin Respir Crit Care Med 1997; 18: 563-570.

96 Freitag L. Tracheobronchial stents. In: Bolliger CT, Mathur PN, eds. Interventional Bronchoscopy. Vol. 30. Basel, Karger, 2000; pp. 171-186.

97 Freitag L, Macha HN, Loddenkemper R. Interventional bronchoscopic procedures. In: Spiro SG, ed. Lung Cancer. Eur Respir Mon 2001; 6: no. 17, pp. 272-304.

98 Stockton PA, Ledson MJ, Hind CR, Walshaw MJ. Bronchoscopic insertion of Gianturco stents for the palliation of malignant lung disease: 10 year experience. Lung Cancer 2003; 42: 113-117.

99 Bolliger CT, Probst R, Tschopp K, Soler M, Perruchoud AP. Silicone stents in the management of inoperable tracheobronchial stenoses. Indications and limitations. Chest 1993; 104: 1653-1659.

100 Bolliger CT, Heitz M, Hauser R, Probst R, Perruchoud AP. An airway Wallstent for the treatment of tracheobronchial malignancies. Thorax 1996; 51: 1127-1129.

101 Miyazawa T, Yamakido M, Ikeda S, et al. Implantation of ultraflex nitinol stents in malignant tracheobronchial stenoses. Chest 2000; 118: 959-965.

102 Monnier P, Mudry A, Stanzel F, et al. The use of the covered Wallstent for the palliative treatment of inoperable tracheobronchial cancers. A prospective, multicenter study. Chest 1996; 110: 1161-1168.

103 Saad CP, Murthy S, Krizmanich G, Mehta AC. Selfexpandable metallic airway stents and flexible bronchoscopy: long-term outcomes analysis. Chest 2003; 124: 1993-1999.

104 Wood DE, Liu YH, Vallieres E, Karmy-Jones R, Mulligan MS. Airway stenting for malignant and benign tracheobronchial stenosis. Ann Thorac Surg 2003; 76: 167-172.

105 Witt C, Dinges S, Schmidt B, Ewert R, Budach V, Baumann G. Temporary tracheo bronchial stenting in malignant stenoses. Eur J Cancer 1997; 33: 204-208.

106 Sutedja G, Schramel F, van Kralingen K, Postmus PE. Stent placement is justifiable in end-stage patients with malignant airway tumours. Respiration 1995; 62: 148-150.

107 Vonk-Noordegraaf A, Postmus PE, Sutedja TG. Tracheobronchial stenting in the terminal care of cancer patients with central airway obstruction. Chest 2001; 120 1811-1814.

108 Vergnon JM, Costes F, Bayon MC, Emonot A. Efficacy of tracheal and bronchial stent placement on respiratory functional tests. Chest 1995; 107: 741-746.

109 Miyazawa T, Miyazu Y, Iwamoto Y, et al. Stenting at the flow-limiting segment in tracheobronchial stenosis due to lung cancer. Am J Respir Crit Care Med 2004; 169: 1096-1102.

110 Colt HG, Meric B, Dumon JF. Double stents for carcinoma of the esophagus invading the tracheo-bronchial tree. Gastrointest Endosc 1992; 38: 485-489.

111 Watanabe S, Shimokawa S, Yotsumoto G, Sakasegawa K. The use of a Dumon stent for the treatment of a bronchopleural fistula. Ann Thorac Surg 2001; 72: 276-278.

112 Tayama K, Eriguchi N, Futamata Y, et al. Modified Dumon stent for the treatment of a bronchopleural fistula after pneumonectomy. Ann Thorac Surg 2003; 75: 290-292.

113 Puma F, Ragusa M, Avenia N, et al. The role of silicone stents in the treatment of cicatricial tracheal stenoses. $J$ Thorac Cardiovasc Surg 2000; 120: 1064-1069.

114 Brichet A, Verkindre C, Dupont J, et al. Multidisciplinary approach to management of postintubation tracheal stenoses. Eur Respir J 1999; 13: 888-893.

115 Noppen M, Poppe K, D'Haese J, Meysman M, Velkeniers B, Vincken W. Interventional bronchoscopy for treatment of tracheal obstruction secondary to benign or malignant thyroid disease. Chest 2004; 125: 723-730.

116 Chhajed PN, Malouf MA, Tamm M, Glanville AR. Ultraflex stents for the management of airway complications in lung transplant recipients. Respirology 2003; 8: 59-64.

117 Gaissert HA, Grillo HC, Wright CD, Donahue DM, Wain JC, Mathisen DJ. Complication of benign tracheobronchial strictures by self-expanding metal stents. J Thorac Cardiovasc Surg 2003; 126: 744-747.

118 Hind CRK, Donelly RJ. Expandable metal stents for tracheal obstruction: permanent or tempory? A cautionary tale. Thorax 1992; 47: 757-758.

119 Hosokawa Y, Tsujino I, Syoda T, Horikoshi A, Sawada S. Examination of expandable metallic stent removed at autopsy. Respirology 2003; 8: 522-524.

120 Noppen M, Pierard D, Mesman M, Claes I, Vincken W. Bacterial colonization of central airways after stenting. Am J Respir Crit Care Med 1999; 160: 672-677.

121 Simoni P, Wiatrak BJ. Microbiology of stents in laryngotracheal reconstruction. Laryngoscope 2004; 114: 364-367.

122 Wells WJ, Hussain NS, Wood JC. Stenting of the mainstem bronchus in children: a word of caution. Ann Thorac Surg 2004; 77: 1420-1422.

123 Zakaluzny SA, Lane JD, Mair EA. Complications of tracheobronchial airway stents. Otolaryngol Head Neck Surg 2003; 128: 478-488.

124 Scherer TA. Nd-YAG laser ignition of silicone endobronchial stents. Chest 2000; 117: 1449-1454.

125 SewallGK, WarnerT, ConnorNP,HartigGK. Comparison of resorbable poly-L-lactic acid-polyglycolic acid and internal Palmaz stents for the surgical correction of severe tracheomalacia. Ann Otol Rhinal Laryngol 2003; 112: 515-521. 